\title{
LA DIPLOMÁTICA SEÑORIAL EN LA CORONA DE CASTILLA
}

\author{
MARIA LUISA PARDO RODRÍGUEZ
}

Hace poco tiempo R.H.Bautier, con ocasión de haberse cumplido cien años del nacimiento de la Escuela Vaticana, publicaba un denso artículo en donde hacía una síntesis muy apretada de las orientaciones de la Diplomática en Europa desde el fín de la segunda guerra mundial '. Y pasando revista a las novedades metodológicas que desde mediados de este siglo se han producido en el campo de esta disciplina, hace notar que los nuevos horizontes pasan irremediablemente por una ampliación de tiempo y contenido ${ }^{2}$ de los estudios de la documentación. En nuestro país, las sugerencias de A. Canellas lanzadas al foro público en el Congreso de Santiago de Compostela, dan un toque de atención sobre la necesidad de trabajos de esta naturaleza, indicando la importancia de que los ojos de los diplomastístas se dirigieran hacia otro tipo de documentos, y otras oficinas de expedición documental que no fuesen las consideradas tradicionalmente como "solemnes" ".

Así, al lado de trabajos sobre los documentos expedidos por las cancillerías regias y pontificias, era preciso abordar la historia de la forma documental en la que se vierte todo tipo de relaciones personales, contractuales y de juridicción de otras instituciones, generadoras igualmente de documentos. Y entre estas, el

$'$ R.H. BAUTIER, Les orientations de la Diplomatique en Europe depuis la fin de la Seconde Guerre Mondiale, en "Cento anni di commincio della Scuola de Paleografia, Diplomatica e Archivistica (1884-1984)", Città del Vaticano, 1986, pp. 101-145.

2 Sería quizás algo excesivo dar aquí un plantel bibliográfico tan amplio, por ello voy a remitirme al sugestivo trabajo de A. PRATESI, Diplomatica in crisi?, publicado en la «Miscelánea Homenaje a G. Cencetti», Turín, 1973, y también al más reciente artículo de G, NicolaJ, Sentieri di Diplomatica, en "Archivio Storico Italiano», CXLIV (1986), pp. 305-331, que recoge su opinión crítica sobre las últimas tendencias que resultan de la relación entre la Diplomática y la Historia Social

${ }^{3}$ A. CANEllas LÓPEZ, La investigación diplomática sobre cancillerias $y$ oficinas notariales: estado actual y posibles investigaciones, en "Actas del Primer Congreso de Metodología aplicada a las Ciencias Históricas», V, Santiago de Compostela, 1975, pp. 201-222. 
análisis de los documentos emanados de un hecho histórico diferencial -el señorío- cobraba carta de naturaleza.

Al mismo tiempo, fue necesario que la Diplomática rompiera la excesiva carga jurídica que siempre le acompañó a la hora de abordar los criterios de la clasificación documental. De hecho, una simple mirada a la manualística tradicional muestra la continua dialéctica documento público-documento privado en la que los especialistas siempre se han movido ${ }^{4}$, enconsertando así la posibilidad de estudiar los documentos más con la mirada histórica que con la jurídica, y eliminando también otro tipo de documentos, que emitidos bajo una cierta forma, no respondían a esta dicotomía. Se privaba así al historiador del documento de un gran volumen de información documental y le impedían llegar a conocer los entresijos de los canales de mediación documental propios de una época histórica concreta, o de una institución determinada en su corriente de civilización.

Superadas estas barreras, no resulta muy explicable que a pesar de que en la corona de Castilla el estudio de los señoríos ha producido y sigue produciendo numerosos trabajos', en el campo específico de la Diplomática sigan siendo muy escasos. De hecho, una ojeada a la bibliografía disponible señala como casi el único foco de estudios, los trabajos de la denominada por R.H. Bautier y J. Trenchs como la nueva escuela de Diplomática de Sevilla, en el Departamento de esta Universidad y que sobre los fondos señoriales del riquísimo Archivo Ducal de Medinacéli estableció dos líneas de investigación, la primera y más antigua la de los documentos catalanes, y la segunda sobre los fondos señoriales castellanos de la Baja Edad Media ${ }^{6}$. También la cancillería del Infante don

4 Citar exhaustivamente la manualística diplomática es un ejercicio algo erudito y no creo que venga al caso. Sí decir que desde H. Bresslau, pasando por A.Giry, C. Paoli, A. de Boüard, G. Tessier y por último A. Pratesi, inciden directamente en el tema o bien siguiendo la tónica de los primeros manuales se sienten obligados a tocarlo. Ese es el caso de G. Tessier y de A. Pratesi, que salva la situación para los documentos señoriales denominándolos como «semipúblicos»

S Véase a este respecto el trabajo de M.C. QuiNTANILLA RASO, Nobleza y señorios en Castilla en la Baja Edad Media. Aportaciones de la bistoriografía reciente, "Anuario de Estudios Medievales», 14 (1984), pp. 613-639, y más recientemente, J.I. ROMERO, El régimen señorial en el tránsito a la Baja Edad Media, "Anuario de Estudios Medievales», 16 (Barcelona, 1986), pp. 106-126; A GUILARTE, El régimen señorial en el siglo XVI, Madrid, 1962; B. Clavero Salvador, Mayorazgo. Propiedad feudal en Castilla (1369-1836), Madrid, 1974; I. AtIENZA HeRNÁNDEZ, Aristocracia, poder y riqueza en la España Moderna. La Casa de Osuna, siglos XV-XIX, Madrid, 1987.

${ }^{6}$ Desde los años setenta puede rastrearse estos estudios para la documentación catalana y para su muestreo remito al trabajo de Pilar Ostos que aparecerá en el tomo homenaje que la Universidad de Valencia prepara dedicado al Dr. Trenchs Odena. Para la castellana véase A.J. LÓPEZ GUTIÉRREZ, Consideraciones sobre la documentación señorial 
Juan Manuel, señor territorial importante en la zona levantina, perteneciente al reino castellano, cuenta con un estudio'.

No obstante, pese a establecer estos estudios una nueva y moderna línea de investigación en lo que se refiere a su temática, tanto los referidos a la documentación catalana como a la perteneciente al reino de Castilla, se ciñen todos al periodo medieval, siendo necesario avanzar más en el tiempo histórico, y no solo porque la moderna Diplomática lo exige, sino también porque el hecho histórico que lo provoca, el señorío, rebasa con mucho su presencia cronológica en la vida de ambos reinos.

Y quizás parte del problema de la no existencia de trabajos sobre estos temas estribe no tanto en la mayor o menor abundancia de fuentes, como ya señalara Moxó ${ }^{8}$, sino en la accesibilidad de los fondos de los mas importantes archivos nobiliarios, que en nuestro país siguen estando en su inmensa mayoría bajo la custodia de propietarios privados, y no en instituciones o depósitos documentales públicos que garantizan la libre consulta de las fuentes archivísticas ${ }^{9}$.

De todas maneras, el historiador del documento que pretenda abordar el

castellana de la Baja Edad Media. Un modelo: Cogolludo, «Gades», 11 (Cádiz, 1983), pp. 121-134; Documentación señorial y concejil del señorio de Cogolludo en el Archivo ducal de Medinaceli (1176-1530), «Historia, Instituciones, Documentos», X (Sevilla, 1984), pp. 1-94; Un documento señorial de nombramiento de escribano en Castilla. 1517, "Saitabi", XXXIV (Valencia, 1984); y Documentación del señorio de Cogolludo en el Arcbivo ducal de Medinaceli de Sevilla (1176-1530), Zaragoza, 1989; M.L. PARDO RODRf́GUEZ, Huelva y Gibraleón. Documentos para su bistoria (1282-1495), Huelva, 1980; Aportación al estudio de los documentos señoriales. El señorío de Medinaceli (1368-1454), en «El pasado histórico de Castilla y León. Edad Media», I, Burgos, 1983, pp. 127-132; Idem, La confirmación en los documentos señoriales de la Baja Edad Media. Aportación a su estudio, "Historia, Instituciones, Documentos", XII (Sevilla, 1985), pp. 247-275; Idem, Los notarios de Medinaceli, «Boletín de la Sociedad Castellonense de culturaw, LXII (Castellón, 1986), pp. 65-75; Idem, La "potestas» señorial: documentos de mandato del condado de Medinaceli, en «Señorío y Feudalismo en la Península Ibérica. Siglos XIII-XIX», Zaragoza, Institución Fernando el Católico (En prensa); Idem, Documentación del condado de Medinaceli (1368-1454), Soria, Excma. Diputación Provincial (En prensa); M.J. SANZ FUENTES, El señorio de Villalonso. aproximación diplomático-bistórica, en «El pasado histórico de Castilla y León. Edad Media», I, Burgos, 1983, pp. 221-232.

7 L. Pascual Martínez, Los oficios y la cancillería en el señorio de Don Juan Manuel, en «Séptimo Centenario del Infante Don Juan Manuel», Murcia, 1982, pp. 259-285.

${ }^{8}$ S. de MoxÓ, Los señorios. Cuestiones metodológicas que plantea su estudio, «Anuario de Historia del Derecho Español», XLIII (Madrid, 1973), p. 273.

9 Fue precisamente la facilidad de la consulta de los fondos del Archivo Ducal de Medinaceli, por parte de don Rafael Medina, duque de Medinaceli, lo que propició las líneas 
estudio de los documentos señoriales en el reino de Castilla, ha de tener en un primer momento muy en cuenta la época que va a analizar, ya que la dilatada vida histórica de los señoríos castellanos conlleva transformaciones fundamentales en el mismo ${ }^{10}$. También la importancia territorial, política y económica del señorío en cuestión y del linaje que lo sustenta van a ser factores fundamentales a la hora de plantear el análisis de la documentación señorial y de los posibles organismos de expedición diplomáticos que lo generan. Y sobre todo ello prevalece el fundamento y la base de lo que significa el regimen señorial en sí, el enmascaramiento de una concreta realidad económica bajo la denominación de una determinada jurisdicción.

A. Iglesia Ferreirós detecta los primeros atisbos de lo que denomina derecho señorial en la época de Alfonso VIII, a través de unos determinados usos y costumbres que llegaran a plasmarse en el reinado de Alfonso $\mathrm{X}$, mediante la tolerancia de estos dentro del poder real, y que individualmente combatirá o reconocerá, al compás de las luchas entre los monarcas y los señores que incardinaron la Baja Edad media castellana. Pero su reconocimiento definitivo se efectuará durante el reinado de Alfonso XI a través del Ordenamiento de Alcalá ", por el que el derecho de los señores es acogido dentro de un marco trazado por la legislación real. Se provoca así un trasvase del derecho regio en el señorial, detectado por Guilarte también en la época moderna ${ }^{12}$ y que consistía en la concesión a los señores de la alta justicia civil y criminal, y con ella la plenitud de jurisdicción denominada por los glosadores como mero e mixto imperio ${ }^{13}$.

De todo ello se desprende que, al igual que los cauces de expresión documental de la potestad real ya formalizados en esta época, el ejercicio del

de investigación antes aludidas y que tantos frutos dio a la investigación diplomática e histórica de nuestro país. Sin embargo, hoy en día la consulta de estos riquísimos fondos se ve interrumpida para algunos miembros de la rescuela sevillana» en cuyos curricula cuentan con numerosas publicaciones al respecto, pero en honor a la verdad éste no es, por desgracia, el único caso. Por ello, hago votos por que la iniciativa del Ministerio de Cultura de crear el Archivo General de la Nobleza en Toledo llegue a buen término, y se permita acceder a todos los investigadores a un patrimonio documental que recoge gran parte de la historia de todos los españoles.

10 Vease la nota 5.

"A. IGLESIA FERREIRÓs, Derecho municipal, derecho setrorial, derecho regio, «Historia, Instituciones, Documentosw, IV (Sevilla, 1977), pp. 142-155; Partida 3,1 y, sobre todo, en la Partida 4, 15, 1 y ss.; Ordenamiento de Alcalá, 27, 3.

12 A. GuilarTe, op. cit., pp. 20 y ss.

13 L. García DE Valdeavellano, Curso de Historia de las Instituciones Espantolas. Desde los origenes hasta el final de la Edad Media, Madrid, 1975, p. 523. 
poder señorial debe de encontrar una formulación adecuada en sus documentos, ya que ellos serán la muestra más palpable de su ejercicio jurisdiccional. Además en ello va a influir, en gran medida, la importancia y amplitud del territorio sobre el que se ejerce y el papel predominante que el linaje o familia que lo detente va a tener en el plano político, social y económico del momento ${ }^{14}$.

Así, la presencia de un mayor o menor número de documentos y, sobre todo, la diversidad de tipos documentales se convierte en una variable a tener en cuenta y es una consecuencia evidente de lo anterior. Ademas, si se quiere abordar la función que el documento tiene en un señorío no importa tanto la cantidad de especímenes como la variedad de formas documentales que adopta, cuáles son éstas, de qué medios culturales, burocráticos y humanos se ha valido el señor de vasallos para su expedición, y por qué y para qué se emplean.

Y para ello resulta válido, en un primer momento, la división y clasificación que desde el punto de vista del marco legal del señorío aporta Salvador de Moxó ", y que incide en la temática de los documentos que establecen las relaciones entre el señor y el o los concejos de los lugares del señorío, los que fijan las relaciones entre el señor y sus vasallos, y, por último aquellos en donde se recogen los lazos de interrelación entre dos o más señores de vasallos. Sin embargo, ante ello la labor del diplomatísta no debe de radicar sólo en traducir a categorías de clasificación documental la escrituración de estos temas, sino tratar de explicar que su expresión formal no es sino producto y ejemplo del uso y empleo de unos «modos» documentales propios de la época que se estudie y, por tanto, adecuados a la expresión de ellos. Por esto se debe de procurar establecer la función que la forma documental ejerce como vehículo de transmisión del poder señorial, y si éste ha procurado un medio de expresión diplomática específico que lo identifica como tal.

En un primer momento, el análisis de los documentos de los señores de vasallos parece indicar que su forme es una clara imitación a la que subyace en los emitidos por la cancillería regia. El caracter mimético con la documentación real ha sido puesta de relieve ya en varias ocasiones ${ }^{16}$, y es tan específica que incluso se puede llegar a establecer una terminología propia en parangón con la acuñada para la documentación emanada de la cancillería del reino de Castilla.

Si los reyes castellanos mediante sus documentos conceden privilegios y

14 M.L. PARdo Rodríguez, Aportación, p. 129.

is S. de Moxó, op. cit., p. 293.

16 Vease la nota 6, y especialmente los trabajos de A.J. LÓPEZ GUTIÉRREZ y de M. L. PARDO RODRÍGUEZ. 
mercedes, los confirman y mandan, también los señores territoriales castellanos van a comportarse de la misma manera en su ámbito jurisdiccional. Poder real y poder señorial van al unísono a la hora de la expresión documental, pero si bien el señor es omnipresente y poderoso en su territorio, su poder emana del rey por concesión, de ahí que las fuentes legales de la época, fiel a la tradición romanísta, establezcan una gradación entre ambos poderes. De esta manera, a la hora del hecho de la documentación, de la expresión de la forma documental y de la aposición de los signos de validación, el sello, símbolo de identificación personal y de poder, restringe y gradua su uso y la cualidad del mismo.

De hecho, el polo de imitación que supone la documentación real-para la señorial funciona casi perfectamente a la hora de imitar la forma de los documentos de los monarcas, y es tan sólo en el campo de los documentos más solemnes en donde se muestra este caracter restrictivo. Los reyes castellanos desde el s. XIII al XV emitirán sus concesiones, confirmaciones y mandatos revestidos de diferentes ropajes documentales: privilegios rodados, cartas plomadas, cartas abiertas, cartas de merced, reales provisiones, reales cédulas, albalaes y cartas misivas. De ellos se emiten en pergamino y validados con sello de plomo pendiente los dos tipos diplomáticos más solemnes, el privilegio rodado y la carta plomada, que acogen siempre los negocios jurídicos mas relevantes en el ejercicio de la soberanía real ${ }^{17}$, y va a ser precisamente en éstos en donde la imitación exacta por parte de los documentos señoriales no va a ser posible.

La reserva que Las Partidas establecen en el empleo del sello de plomo para uso exclusivo del monarca castellano ${ }^{18}$, así como de poder conceder privilegios ${ }^{19}$, condiciona el hecho de que el señor de vasallos a la hora de conceder 0 confirmar, lo haga de mercedes y con sello de cera pendiente o de placa, dependiendo esto último de la época de que se trate. Pero a excepción de esta salvedad legal, por la que el rey preserva su poder sobre otros, el conjunto de caracteres externos e internos de los documentos señoriales no hacen sino afirmar que el modelo documental a imitar no puede ser otro que el real, al ser entre todos los modos escriturarios de la época el que presentaba el más alto nivel de representación de la jurisdicción civil, con la simbología que lleva implícita. Se diría, pues, que dentro de la jerarquía de valores y la especialización que representan las formas documentales en los siglos bajomedievales, el señor de vasallos y su entourage político y burocrático fueron conscientes de que se estableciera unos cauces de mediación documental, y no tanto a través del

17 M.J. SANZ FUentes, Tipología documental de la Baja Edad Media castellana. Documentación real, en "Archivística. Estudios básicos», Sevilla, 1981, pp. 241-256.

18 Partida 3,18,1

19 Partida $3,18,2$ y $26 .-3,24,1$ 
contenido de los diplomas que de él o de ellos emanaban, sino a través del ropaje de los mismos.

La confirmación, como práctica documental, se muestra en las fuentes legales de la época -Espéculo y Partidas- y en los documentos reales como uno de los usos más frecuentes de la diplomática castellana ${ }^{20}$, y si se acude a los documentos de concesión y confirmación señoriales son muchos los elementos del dicurso diplomático que recuerdan e imitan la expresión documental de los procedentes de los monarcas. De hecho, la confirmación señorial puede mostrar dos elementos básicos en su concepción documental. Uno se refiere a que al igual que la llegada de un nuevo reinado provoca una actividad confirmatoria de la cancillería real, cuando acontece un cambio en la titularidad del señorío, las oficinas de expedición señoriales se comportan de la misma manera, y otro, que también la confirmación ofrece una mayor o menor artículación y complicación del discurso diplomático dependiendo de la inserción o no del documento a confirmar.

Y si nos adentramos en el análisis formal se ve que:

- se emiten en pergamino ${ }^{21}$, reservandose el papel, como materia sustentante, para los procedentes del $\mathrm{s}$. $\mathrm{XV}^{22}$, precisamente cuando la cancillería real castellana ha creado un nuevo tipo documental en papel, la carta de merced, que iniciando su redacción por la intitulación recoge concesiones de mercedes.

- las titulaturas expresan siempre el título y en muchas ocasiones la expresión de dominio.

- la exposición se articula mediante la motivación de merced, la recompensa a los servicios prestados, y en el caso de las inserciones la vista, la petición y el acceso a ella por parte del señor.

- cerrando la disposición, logicamente concesiva o confirmativa, aparecen junto a las habituales claúsulas yusivas y las conminatorias, otras que muestran la ira señorial, en evidente parangón con las reales.

- el anuncio de validación presenta siempre la máxima validación permitida por la legislación coetanea para los señores territoriales laicos. Así, para los documentos en pergamino expresa la validación del sello pendiente de cera, que

20 T. MARÍN MARTÍNEZ, Confirmación real en documentos castellanos-leoneses, "Estudios dedicados a R. Menéndez Pidal», III. Madrid, 1951, pp. 583-593; L. SÁNCHEZ BELDA, La confirmación de documentos por los reyes en el Occidente español, «Revista de Archivos, Bibliotecas y Museos», VI (1953), pp. 85-116; M.J. SANZ FUENTES, La confirmación de privilegios en la Baja Edad Media. Aportación a su estudio, "Historia, Instituciones, Documentos», VI (Sevilla, 1979), pp. 341-367.

${ }_{21}$ A.J. LÓPEZ GuTIÉRREZ, Documentación, docs. núms. 6 y 7; M.L. PARDO RODRÍGUEZ, Confirmación, docs. 1-6; y Huelva y Gibraleón, docs. núms. 6, 7 y 8.

${ }_{22}$ A. J. LÓPEZ GuTIÉRREZ, Documentación, docs. núms. 30, 32, 46 y 48. 
en el caso de los la Cerda, condes de Medinaceli, y herederos directos de Alfonso $\mathrm{X}$, será de cera roja ovalado ${ }^{23}$. Cuando la concesión o confirmación se emite en papel, en el siglo XV, se valida mediante el sello mayor de placa ${ }^{24}$. También, suelen en él asignarse calificaciones del documento en cuestión como la de carta abierta, confirmación de privilegio o carta de merced.

- la suscripción suele ser señorial, y de hecho ésta asume como casi única este momento validatorio, expresando el nombre o bien el título nobiliario que le corresponda, pero a veces aparece la notarial, si bien explicita mediante la locución a la su mersed su pertenencia al notariado público que ejerce su oficio en lugar de señorío.

Y de esta forma documental los señores de vasallos van a valerse para establecer su relación jurisdiccional con los concejos de su señorío, haciendo concesiones y mercedes de dehesas de uso comunal, como las de Estriégana y Montuenga, dos lugares del condado de Medinacéli, o entre otras muchas cosas, de una feria anual a Gibraleón, lugar perteneciente también a la familia La Cerda desde $1306^{23}$, y confirmandoles las mercedes concedidas por los titulares anteriores del señorío. También en su relación con los vasallos, bien a nivel particular, como es el caso de la anuencia señorial a la explotación de las salinas de Almalla por parte de Juan Duque, ya vasallo de los Medinacéli, bien a instituciones religiosas que estaban en su territorio como el monasterio de Buenafuente del Cistal o el de Santa María Magdalena de la villa de Medinaceli.

De la misma manera, los documentos de mandato señoriales establecerán los cauces de mediación documental de los señores de vasallos, tanto en su relación necesaria con otros señores, que afectan o pueden afectar al ámbito territorial del señorío, como las relaciones que se establecen con los concejos de este mismo territorio ${ }^{26}$. Y de nuevo, el mimetismo con respecto a la documentación real los caracteriza.

Al igual que ésta, los documentos yusivos de los señores territoriales encuentran una formulación específica según si el caracter del mandato es imperativo, rogado o pedido. Reales provisiones, albalaes, reales cédulas y misivas de caracter oficial o particular presentan dentro de unas características comunes un formulario distintivo, y su uso estará en función de la importancia y trascendencia del contenido. Y de la misma manera las provisiones y los albalaes señoriales revestirán el formulario más complejo y se emplearán por parte del señor para señalar dehesas, para otorgar ordenanzas concejiles o para

23 M.L. PARdo Rodriguez, Huelva y Gibraleón, doc. núm. 6.

${ }^{24}$ A.J. LÓPEZ GuTIÉRREZ, Documentación, docs. núms. 30, 32, 46 y 48, y pp. 117 118.

25 M.L. PARdo RodrígueZ, Huelva y Gibraleón, p. 52.

${ }^{26}$ M.L. PARDO RODRÍGUEZ, La "potestas", p. 2 (En prensa). 
dar instrucciones concretas a los concejos de su señorío, reservándose las misivas bien para la comunicación entre señores, bien para procurar el cumplimiento de una orden inmediata a personas de su entorno ${ }^{27}$.

Sus elementos formales más característicos son: y XV.

- Su emisión en papel, al igual que los documentos reales de los siglos XIV

- El inicio intitulativo y el consiguiente desarrollo de la expresión de dominio. Tan solo en las misivas se inicia la redacción documental por la dirección, debido a su caracter de documento más cercano e inmediato y que a la hora de procurar su cumplimiento se reviste de otros elementos.

- La salutación está presente en todos, pero a la hora de su expresión formulística al escueto y protocolario Salud e grạ̧ia de las provisiones, se le añade, en el caso de los albalaes y las misivas, la fórmula de aprecio tan típica de las misivas reales que no es sino la necesidad de una captatio benevolentiae precisa para llevar a buen término la finalidad del documento.

- La validación mediante sello mayor de placa en el caso de las provisiones. También, como en los documentos concesivos y confirmativos la suscripción señorial está en evidente relación con la que aparece en los documentos reales de mandato.

Así, el señor ejerce su poder también mediante las provisiones, albalaes y cartas misivas, pero los niveles de relación que se establecen en el empleo de un medio documental u otro estribará, así mismo, de la cualidad de la persona o institución a quien se dirija. Por ello, necesitará de otros caminos documentales para plasmar otro tipo de asuntos, que sin duda inciden también en la vida del señorío y que en este caso viene condicionado por las circunstancias políticas del reino castellano en la Baja Edad Media o por la entidad del destinatario.

Desde luego, cuando un señor se dirige a la máxima autoridad del reino, el rey, lo hará mediante peticiones o memoriales en donde se plama lo que se solicita, y la forma diplomática que adopta será la heredera de los usos epistolares de la época romana, y que a través de la retórica pervivieron y se desarrollaron en la época medieval. Esta consideración, sin embargo, no es precisa a la hora de poner por escrito las múltiples alianzas y acuerdos que la nobleza castellana practicó a lo largo de los últimos siglos medievales y de las que hay cumplida cuenta en los depósitos archivísticos señoriales, sobre todo de

27 A fin de evitar reiteraciones en las notas, para este tema concreto, me remito a A.J. LópeZ GuTIÉRREZ, Documentación, docs. núms. 10, 21 y 51; M.L. PARDO RODRÍGUEZ, Huelva y Gibraleón, docs. núms 59 y 60; Idem, La «potestas», docs. 1-12. (En prensa); Idem, Las ordenanzas municipales de Puebla de Cazalla de 1504, «Actas del Segundo Congreso de Historia de Andalucía» (En prensa). 
la segunda mitad del s. XV. Me refiero a las confederaciones nobiliarias, que no son sino pactos de ayuda mutua y que intituladas por ambas partes cuentan con una formulación precisa y con una validación dúplice en tanto que se aponen sendos sellos de placa, y es suscrita por ambas partes ${ }^{28}$.

Por último, me falta por señalar aquí las relaciones documentales que el señor de vasallos establece, no en ejercicio de su jurisdicción sino como un habitante más de su señorío. Su incidencia en el ámbito de las relaciones privadas y particulares hacen que use la oficina de expedición documental idónea, el notariado, y que las categorías diplomáticas de sus documentos sean las mismas que la Partida III, en sus títulos XVIII y XIX señala para la documentación notarial y de caracter privado.

Ante esta presencia formal cabe preguntarse, ahora, cuáles son los medios sociales, culturales y humanos que la han hecho posible. La regulación escrituraria de la vida del señorío debió de contar con unos organismos de expedición documental, subsidiarios del poder establecido, que formalizaran y encauzaran las vias de mediación documental necesarias en el desenvolvimiento de la institución y de la realidad histórica que representa. Y también, de unos profesionales de la escritura cualificados para el desempeño de tal función.

Así, sería preciso contar con:

- una oficina de expedición documental que variará en su composición y en las funciones a realizar si se trata de atender al señor de vasallos en el ejercicio de su "potestas», con lo que habría que plantear la existencia o no de cancillerías señoriales. $O$ bien si el señor actúa como un particular, al igual que el resto de los habitantes del señorío -el notariado público de la época- .

- los medios humanos, las personas que formaban parte de estas oficinas y que en la época bajomedieval presentaban ya un perfil profesional. Ello conlleva al conocimiento, por una parte, del notariado señorial, en evidente similitud con el escribano cancilleresco del rey, y por otra, al del notariado público que desempeña su función en los lugares del señorío.

- los medios culturales de ayuda a la documentación, los formularios usados por estos profesionales que, en el caso de los documentos utilizados en el gobierno del señorío muestran un mimetismo claro con respecto a los reales, con lo que el foco de información será el que en la corona castellana estuvo

${ }^{28}$ Es el caso de la confederación de 1470, entre Luís de la Cerda, V conde de Medinaceli y señor del Puerto de Santa María, y don Enrique de Guzmán, duque de Medina Sidonia, en M.L. PARDo RodríGUEZ, Huelva y Gibraleón, doc. núm. 88; y el de 1443, entre Luis de la Cerda, III conde de Medinaceli e Iñigo López de Mendoza, señor de la Vega, en M.L. PARDo RodRígueZ, Documentación, doc. núm. 188. 
vigente hasta los inicios de la modernidad, los que recogen las Partidas. Al lado de ello, los documentos notariales del señorío tendrán el auxilio de los formularios notariales vigentes en el mismo periodo en el reino de Casti$11{ }^{29}$.

Contamos con pocos datos para poder desentrañar la existencia fehaciente de las cancillerías señoriales y de su nivel de organización y especialización de funciones. La ausencia ${ }^{30}$, por ahora, de registros cancillerescos señoriales hace que las fuentes de información a este respecto se centren en los documentos señoriales o en otros que nos puedan aportar noticias indirectas, así como en la literatura de la época. Y todo ello hace pensar no solo en la necesidad de su existencia sino en su muy posible realidad histórica ${ }^{31}$. La especialización que subyace en la forma diplomática adoptada por los documentos señoriales, la jerarquía de valores que lleva implícita el uso selectivo de los medios de validación mediante sello -sello de cera pendiente, sello de placa mayor y menor- y los momentos genéticos de la elaboración documental que se traslucen, llevan a este camino. También las menciones a los profesionales que desempeñaban cargos o funciones documentarias - canciller y escribanos, y desde fines del s. XV el secretario ${ }^{32}-$.

Es más, se podría añadir a estos datos la valoración consciente que del tema hay en la sociedad de la època. El infante don Juan Manuel, señor de vasallos de linaje regio va a ser su portavoz a través de la obra «El libro de los Estados», en donde expresa la teoría política del momento y donde afirma,

${ }^{29}$ Junto a la regulación legal en el campo del notariado que supone las Partidas -Partida 3,18 y 19- y que contiene un auténtico formulario notarial, al igual que en el campo de la documentación real, se conocen como vigente en la practica documental castellana, el editado por $\mathrm{Galo}$ Sánchez, anónimo, pero según Bono atribuible a un notario de Ávila y que data del reinado de Enrique III, otro editado por Luisa Cuesta, también anónimo y perteneciente al reinado de Juan II, y el conocido como Las notas del relator, de Fernán Díaz de Toledo, referendario de Juan II y oidor de la Audiencia real, y que Bono considera de gran influencia en su época y en el s. XVI. Vease J. BONO HuERTAS, Historia del Derecho notarial español, 2, Madrid, 1982, pp.59-72.

${ }^{30}$ La ausencia no significa carencia. Un botón de muestra en este sentido es la perdida de los registros de las cancillerías reales castellanas hasta los RR.CC. y todos los datos indican su existencia reglada desde el reinado de Alfonso VII.

${ }^{31}$ A.J. LÓPEZ GUTIÉREZ, Documentación, pp. 99-1 18.- M.L. PARDo RODRíGueZ, La confirmación, pp. 249-256; Idem, Huelva y Gibraleón, pp. 30-38; Idem, Los notarios, pp. 74-75; L. PASCUAl MARTíneZ, Los oficios y la cancillería, pp. 264-284.

${ }_{32}$ Pese a no ser un cargo estrictamente cancilleresco, M. Soterraña Martín Postigo señaló su importante intervención documental en la cancillería de los RR. CC.. Lo mismo puede constatarse en los documentos de los condes, luego duques de Medinacéli como transmisor de la iussio señorial. Vease A.J. LÓPEZ GUTIÉRREZ, Documentación, p. 116.También en unos especímenes del Archivo de la Catedral de Sevilla, ACS, caja 26, 2 y 11 
entre otras cosas, que el cargo de canciller es: «el más honrado ofiçio et de mayor prow, y a continuación, le señala sus importantes cometidos "'.

Por otra parte, en el señorío está presente también otra oficina documental, el notariado, pero que, al contrario que la cancilleresca, no es específica de este regimen señorial. Presente en todos los territorios del reino de Castilla, su desenvolvimiento será el mismo trátese de lugares de realengo o de señorío, pero en este último caso la institución señorial establece un elemento corrector necesario. Debido a que el notariado será el soporte escriturario del poder dominante real, y dado que el trasvase de poder del rey al señor es un hecho, la potestad de creación de notarios en zonas de señoríos pasará también a manos del poder señorial. De ahí que en los documentos de concesión de señoríos los reyes especifiquen esta cuestión que se refleja en las suscripciones de escribanos públicos que desempeñaban su oficio en tierras señoriales con la locución a la su mersed. No obstante y a pesar de ello, su actuación documental recorre paso a paso los mismos caminos que el resto de sus colegas del reino ${ }^{34}$.

Así, los señores de vasallos castellanos debieron asegurar su poder mediante la creación de un organismo de expedición propio, llámese cancillería o no, cuya funcionalidad estriba en ser el soporte de su potestad, ya que garantiza documentalmente el orden socio-político establecido, y, por otra parte, controlan la otra oficina documental, el notariado, sustento de un ámbito de poder superior, el real, en constante pugna con los señores castellanos.

Por último, cabría plantear aquí otro interrogante. A lo largo de este corto recorrido he aludido con una cierta frecuencia a un factor extradocumental que considero fundamental a la hora de explicar el lenguaje diplomático de los señoríos, y es que los estudios sobre la diplomática señorial castellana se han realizado sobre linajes y señoríos que alcanzaron un nivel de representación social, político y económico muy elevado en su época. El protagonismo que ellos tuvieron habría que situarlo en el más alto escalón de la nobleza castellana, y, por lógica, su punto de mira estaría situado hacia el poder superior más cercano, el real, y ello se traduce en los cauces de mediación documental que antes he analizado.

Pero, cuál es la realidad documental de esos otros señores cuyo ámbito de poder se limita a un territorio menos extenso, y que tienen un protagonismo social y político menos acusado. Sería lógico pensar que éstos no necesitarían recurrir a la función instrumental y simbólica que conlleva la elaboración y la forma de documentos propios, señoriales, ni de la existencia de una oficina de

${ }^{33}$ Infante DON JUAN MANUel, El libro de los Estados, I, XCIV y XCV.

${ }^{4} \mathrm{~J}$. BONO HUERTAS, op. cit., Pp. 155-172; A.J. LÓPEZ GUTIÉRREZ, Un nombramiento de escribano; M.L. PARDO RODRÍGUEZ, Los notarios. 
expedición específica. De esta manera, la imagen dada de la documentación señorial se distorsiona o puede distorsionarse en función de que la existencia o no de los medios burocráticos y humanos, y en el caso de su existencia, la mayor o menor complejidad burocrática y la mejor o peor formación o cualidad de los profesionales de la escrituración dependerá de la importancia social, política y económica de los linajes detentadores de señorío.

Muchas son, pues, las cuestiones que suscita el estudio de los documentos señoriales. Estas podrán afirmarse o rebatirse cuando se pueda disponer de un plantel mas amplio de trabajos, y consecuentemente, de información, pero sí diría que, a modo de conclusión, su estudio, en el reino de Castilla o en cualquier otro ámbito histórico o geográfico del mundo occidental, solo puede ser posible desde nuestra disciplina con una visión «moderna» de ella. Y que a mi entender pasa por desentrañar la funcionalidad de la documentación en una institución o hecho histórico diferencial en una época concreta, de manera sincrónica o diacrónica, dependiendo de su pervivencia en el tiempo. Para ello el diplomatista se vale del estudio de la forma documental, de las personas que la realizaron, de los medios burocráticos y culturales usados para la escrituración, e intenta averiguar los cauces de mediación documental que se establecen entre los distintos grupos o personas que, en el caso que nos ocupa, formaron parte del complejo mundo del regimen señorial.

\section{RÉSUMÉ}

Dans le cadre de la Couronne d'Aragon, l'étude des documents seigneuriaux, du point de vue de l'historien qui étudie le document, a été l'objet, ces dernières années, de travaux significatifs, mais qui s'avèrent encore insuffisants pour permettre une reponse complète à toutes les questions que pose cette même documentation.

Le présent travail prétend offrir un état de la bibliographie la plus récente et en même temps un exposé méthodologique qui permettent d'aborder l'étude des documents seigneuriaux castillans avec une vision «moderne» de la Diplomatie. Une telle attitude n'est réalisable qu'en s'occupant du «fonctionnalisme» du document dans le contexte historique dans lequel il se déroule et s'utilise en tant qu'instrument de pouvoir.

À travers l'étude de la forme documentaire, des personnes qui le réalisèrent, des moyens bureaúcratiques et culturels utilisés pour son écriture, il est possible de suivre la trace des courants de médiation des écrits, courants établis entre les diverses institutions et personnes qui font partie du monde complexe qu'est celui du régime seigneurial. 


\section{SUMMARY}

In the framework of the Crown of Aragon, the study of the seigniorial documents, from the point of view of an historian who studies the document, has been the subject, during the last few years, of significative -but insufficient- works to give a complete answer to all the questions that this very documentation arouses.

The present work wants to offer an approach of the most recent bibliography and a methodological account that would allow us to study Castilian seigniorial documents from the modern point of view of Diplomacy. Such an attitude is only possible if the "functionalism" of the document is taken into account, in the historical context in which it takes place and in which it is used as an instrument of power.

Through the study of the documentary form, of the people who realised it, of the bureaucratic and cultural means used for its writing, it is possible to follow the path of the trends of mediation of the documents. These trends were established between the different institutions and persons who belonged to the complex world of the seigniorial regime. 